\title{
Rapid Validated Stability Indicating Method for Nizatidine and its Impurities Quantification
}

\author{
Antony Raj Gomes ${ }^{1,2}$, Pannala Raghuram ${ }^{1,2}$, J. Sriramulu ${ }^{2}$, Nimmakalaya Srinivas ${ }^{1}$ \\ ${ }^{1}$ Shasun Chemicals and Drugs Limited Company, Chennai, India \\ ${ }^{2}$ Department of Chemistry, Sri Krishna Devaraya University, Anantapur, India \\ E-mail:vas.sri328@gmail.com \\ Received November 10, 2010; revised March 7, 2011; accepted April 3, 2011
}

\begin{abstract}
This research article describes stability indicating fast liquid chromatographic method for determination of chromatographic purity and assay of Nizatidine as a alternate for two different methods for chromatographic purity and assay as given in USP Monograph and Ph.Eur Monograph. Proposed method is developed on Waters symmetry RP18 $(50 \times 4.6 \mathrm{~mm}), 3.5 \mu \mathrm{m}$ stationary phase using gradient elution with combination of Ammonium acetate Diethyl amine buffer, Methanol and Tetrahydrofuran as mobile phase. Favorable results are obtained under developed conditions, which guarantee good separation of studied components. Whereas, data obtained from method validation confirm specificity, high sensitivity, linearity in a range of studied concentrations, repeatability and good accuracy of this method. Considerable degradation observed in oxidation stress condition was detected by this method. Eight impurities are studied among which impurity-5 is found major degradant. The stress samples are assayed against a qualified standard and the mass balance is found close to $99.2 \%$. The developed method can be used for routine samples as well as stability studies.
\end{abstract}

Keywords: Column Liquid Chromatography, Nizatidine, Forced Degradation, Validation; Stability Indicating

\section{Introduction}

Nizatidine: $N$-(2-[(2-[(dimethylamino)methyl]thiazol-4yl)methylthioc]ethyl)- $N$-methyl-2-nitroethene-1,1-dimine . Nizatidine is a histamine $\mathrm{H}_{2}$-receptor antagonist that inhibits stomach acid production, and commonly used in the treatment of peptic ulcer disease (PUD) and gastroesophageal reflux disease (GERD). It was developed by Eli Lilly and is marketed under the trade names Tazac and Axid Certain preparations of Nizatidine are now available over the counter in various countries including the United States. Nizatidine has been used experimentally to control weight gain associated with some antipsychotic medication [1-3].

Nizatidine is having monographs in USP [4], Ph.Eur [5]. USP monograph describes a chromatographic purity method with a runtime of 70 minutes and separate assay method with a runtime of 40 minutes. The Ph.Eur monograph describes a related substances method with a runtime of 60 and assay method with a run time of $25 \mathrm{mi}-$ nutes. We have attempted in this paper a common method for impurities and assay determination which is fast and economic. In the literature survey there is no fast LC stability indicative methods are reported for chromatographic purity and assay for Nizatidine. Validation of chromatographic purity and assay determination methods for accurate quantification of eight impurities and in $\mathrm{Ni}$ zatidine samples along with assay determination is described in this paper is carried out as per ICH recommendations. Intensive stress studies were carried out for possible degradants identification and degradation pathway is established for Nizatidine with validated proposed method.

\section{Experimental Design}

\subsection{Chemicals}

Samples of Nizatidine with purity of more than 99.5\% and its related impurities having purity more than $97.0 \%$ are received from Shasun research centre, Chennai, India (Figure 1). HPLC grade methanol and tetrahydrofuran are purchased from Merck, Darmstadt, Germany. Analytical reagent grade ammonium acetate and diethyla- 
mine are purchased from Merck, Darmstadt, Germany. High purity water is prepared by using Millipore Milli-Q plus water purification system.

\subsection{Procedure}

\subsubsection{Equipment}

The LC system, used for method development and method validation is Agilent RRLC. The output signal is monitored and processed using EZ-Chrome elite software on Pentium computer (Digital equipment Co). RRLC is equipped with binary gradient pump, thermostatted auto sampler, thermostatted column compartment, variable wavelength detector.

\subsubsection{Chromatographic Conditions}

The chromatographic column used is Waters Symmetry RP18 $(50 \times 4.6 \mathrm{~mm})$ with $3.5 \mu \mathrm{m}$ particles. The mobile phase-A contains a $0.05 \mathrm{M}$ of ammonium acetate and 1.0 $\mathrm{mL} \cdot \mathrm{L}^{-1}$ diethylamine. Methanol and tetrahydrofuran (95:5) is used as mobile phase-B. The flow rate of the mobile phase is $1.5 \mathrm{~mL} \cdot \mathrm{min}^{-1}$ with a gradient program of 0/2, 2/10, 7/35, 9/45, 10/2 and 12/2 (time (min)/\% B).The column temperature is maintained at $30^{\circ} \mathrm{C}$ and the detection is monitored at wavelength of $254 \mathrm{~nm}$. The injection volume is $10 \mu \mathrm{L}$.

Diluent consists buffer and methanol in the ratio 80:20.

\subsubsection{Preparation of Standard and Sample Solutions:}

All the impurities are dissolved in diluents having concentration of $0.1 \mathrm{mg} / \mathrm{mL}$ then make up to the volume with diluent. A Stock solution of Nizatidine $\left(2000 \mu \mathrm{g} \cdot \mathrm{mL}^{-1}\right)$ is prepared by dissolving appropriate amount in the diluent. Working solution $200 \mu \mathrm{g} \cdot \mathrm{mL}^{-1}$ is prepared from above stock solution for assay determination.

\subsection{Method Development and Optimization}

The USP [4] method for Nizatidine chromatographic purity determination has a run time of 70 minutes with $1.0 \mathrm{~mL} \cdot \mathrm{min}^{-1}$ flow rate. And the European pharmacopeia [5] method for Nizatidine chromatographic purity determination has a run time of 60 minutes with $1.0 \mathrm{~mL} \cdot \mathrm{min}^{-1}$ flow rate. The main objective of the present study is to develop a method having less runtime which can be use for both chromatographic purity and assay determination. To calculate the flow rate we have used the formula in USP pharmacopeial forum Stimuli article "Transfer of HPLC Procedures to Suitable Columns of Reduced Dimensions and Particle Sizes" [6].

$$
F_{2}=F_{1} \times 1_{2} \times d_{2}^{2} / 1_{1} \times d_{1}^{2}
$$

where $\mathrm{F}, \mathrm{l}$, and $\mathrm{d}$ are the flow rates, the column lengths, and the column diameters, by this formula a flow rate of $0.2 \mathrm{~mL} \cdot \mathrm{min}^{-1}$ was derived from USP method parameters and by using the USP method details to short length column and flow specified but when attempted Nizatidine peak elute around 32 minutes and impurity-3 (last eluting impurity) elute around 60 minutes with low response.

Flow rate arrived from existing USP method is 0.2 $\mathrm{mL} \cdot \mathrm{min}^{-1}$ was derived for $50 \times 4.6 \mathrm{~mm}$ column in which a late elution was found. To decrease the run time flow rate has increased 7.5 times i.e. $1.5 \mathrm{~mL} \cdot \mathrm{min}^{-1}$ when applied in this condition Nizatidine peak elutes around 4.8 minutes and last impurity elutes around 11 minutes with low response. For decreasing the retention time and to raise the response of impurity-3, 5\% tetrahydrofuran introduced in to the mobile phase-B. In this condition impurity-3 retention time decreased to 8.2 minutes from 11 minutes and peak responses also enhanced. The typical retention times of Nizatidine, impurity-1, impurity-2, impurity-3, impurity-4, impurity-5, impurity-6, impurity7 and impurity-8 were about 4.801, 5.719, 2.595, 8.392, 7.381, 2.930, 2.211, 0.646 and 3.231 minutes respectively meeting the chromatographic system suitability requirements.( See Table 1)

\subsection{Analytical Method Validation}

The developed chromatographic method is validated for specificity and stress studies, sensitivity, linearity \& range, precision, accuracy, and robustness and system suitability for both chromatographic purity and assay methods [7-15].

\subsubsection{Specificity and Stress Studies}

Specificity is the ability of the method to measure the analyte response in the presense of its potential impurities. The specificity $[10,11]$ of the developed LC method for Nizatidine was determined in the presence of its impurities namely impurity-1, impurity-2, impurity-3, impurity-4, impurity-5, impurity-6, impurity-7 and impurity-8 at a concentration of $30 \mu \mathrm{g} \cdot \mathrm{mL}^{-1}$. The stress conditions employed for degradation study includes photolytic (carried out as per ICH Q1B), thermal $\left(80^{\circ} \mathrm{C}\right)$, acid hydrolysis (1 N HCl), base hydrolysis (0.1 N NaOH), hydrolysis and oxidation ( $\left.10 \% \quad \mathrm{H}_{2} \mathrm{O}_{2}\right)$.Peak purity of stressed samples of Nizatidine was checked by using 2996 Photo diode array detector of Waters (PDA). All stressed samples of Nizatidine were analysed for an extended run time of 15 minutes to check the late eluting degradants.

Assay was carried out for stress samples against qualified reference standard and the mass balance (\% assay 
Table 1. System suitability report.

\begin{tabular}{cccc}
\hline Component & USP Resolution $\left(R_{s}\right)$ & USP Tailing factor & \% RSD at Precision study \\
\hline Impurity-7 & -- & 1.0 & 0.11 \\
Impurity-6 & 12.9 & 1.0 & 0.71 \\
Impurity-2 & 3.4 & 1.1 & 1.35 \\
Impurity-5 & 3.0 & 1.0 & 0.63 \\
Impurity-8 & 2.7 & 1.1 & 0.39 \\
Nizatidine & 13.3 & 1.0 & 0.49 \\
Impurity-1 & 6.6 & 1.0 & 0.65 \\
Impurity-4 & 11.2 & 1.0 & 0.50 \\
Impurity-3 & 7.3 & 1.0 & 0.80 \\
\hline
\end{tabular}

Table 2. Summary on forced degradation results.

\begin{tabular}{|c|c|c|c|c|c|}
\hline Stress condition & Time & $\begin{array}{c}\text { \% Assay of active } \\
\text { substance }\end{array}$ & $\begin{array}{l}\% \text { impurities + \% De- } \\
\text { gradation products }\end{array}$ & $\begin{array}{c}\text { Mass balance (\% Assay + \% } \\
\text { impurities + \% Degradation } \\
\text { products) }\end{array}$ & Remarks \\
\hline Acid (1 N HCl) & 2 hrs heating at $80^{\circ} \mathrm{C}$ & 98.3 & 1.0 & 99.3 & $\begin{array}{l}\text { No significant degrada- } \\
\text { tion is observed }\end{array}$ \\
\hline $\begin{array}{c}\text { Base }(0.1 \mathrm{~N} \\
\mathrm{NaOH})\end{array}$ & 10 minutes heating at $80^{\circ} \mathrm{C}$ & 98.1 & 1.4 & 99.5 & $\begin{array}{l}\text { No significant degrada- } \\
\text { tion is observed }\end{array}$ \\
\hline $\begin{array}{c}\text { Peroxide }(10 \% \\
\left.\mathrm{H}_{2} \mathrm{O}_{2}\right)\end{array}$ & 0 hrs (Fresh) & 85.5 & 15.1 & 100.6 & Formation of impurity-5 \\
\hline Thermal (at $80^{\circ} \mathrm{C}$ ) & 24 hrs & 98.0 & 1.2 & 99.2 & $\begin{array}{l}\text { No significant degrada- } \\
\text { tion is observed }\end{array}$ \\
\hline $\begin{array}{l}\text { Photo light stressed } \\
\text { sample }\end{array}$ & 1200 Klux hours & 99.3 & 0.8 & 100.1 & $\begin{array}{l}\text { No significant degrada- } \\
\text { tion is observed }\end{array}$ \\
\hline
\end{tabular}

+\% of impurities +\% of degradation products) was calculated for all the samples.

\subsubsection{Precision}

The precision of the chromatographic purity method is checked by injecting six individual preparations of (2000 $\mu \mathrm{g} \cdot \mathrm{mL}^{-1}$ ) Nizatidine spiked with $0.03 \%$ each impurity. The \% RSD for content of each impurity is calculated.

The intermediate precision (ruggedness) of the method is evaluated by different analyst using different column and different day in the same laboratory.

The precision of the assay method is evaluated by carrying out six independent assay of test sample of Nizatidine against a qualified reference standard. The \% RSD of six obtained values is calculated. 95\% confidence interval of mean has to be calculating for both \% of each impurity and \% of assay.

\subsubsection{Sensitivity}

Sensitivity was determined by establishing the Limit of detection (LOD) and Limit of quantification (LOQ) for each component estimated by based on the Signal to noise ratio method. The precision study was also carried out at the LOQ level by injecting six replicates and calculated the \% RSD for the area of each impurity and Nizatidine.

\subsubsection{Linearity and Range}

Linearity test solutions from LOQ to $150 \%$ with respect to test concentration are prepared by diluting the impurity stock solution to the required concentrations. For assay method test solutions from $50 \%$ to $150 \%$ with respect to test concentration are prepared by diluting the stock solution to the required concentrations. The correlation coefficient, slope and Y-intercept of the calibration 


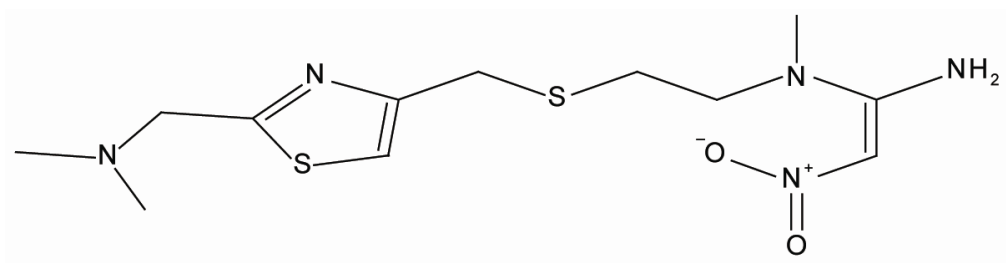

(a)

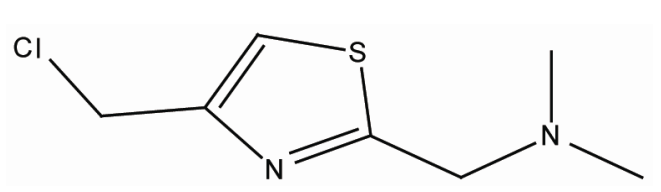

(b)

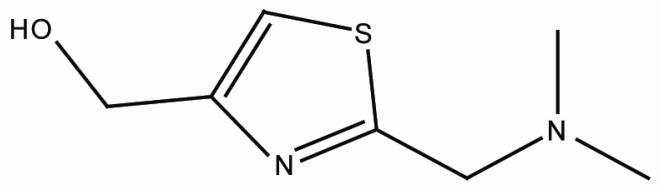

(c)<smiles>CN(C)Cc1nc(CSCCN(CCSCc2csc(CN(C)C)n2)/C(N)=C\[N+](=O)[O-])cs1</smiles>

(d)

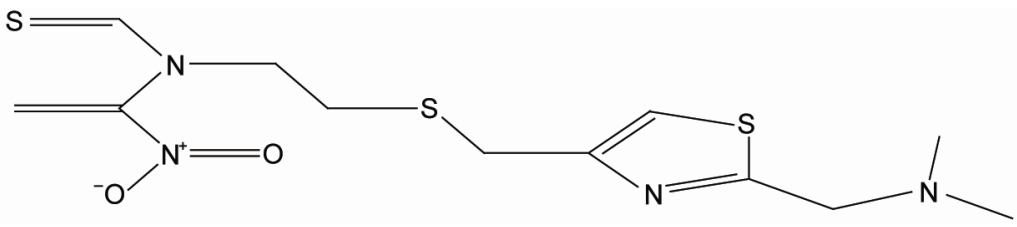

(e)

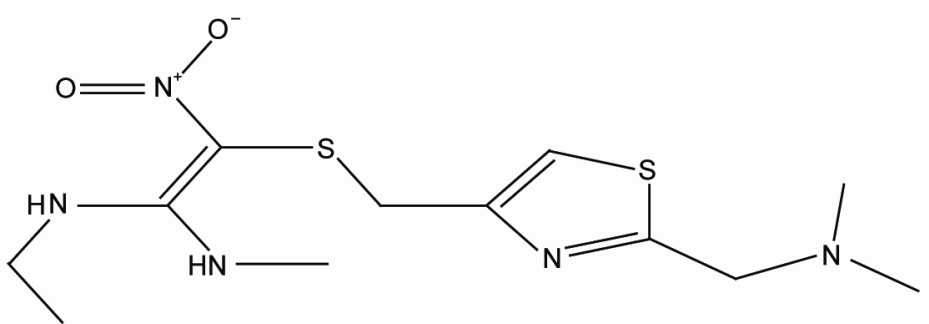

(f)

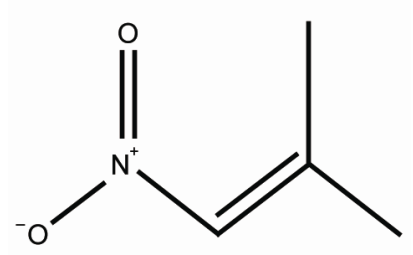

(g)<smiles>C/C=C\[N+](=O)[O-]</smiles>

(h)<smiles>CNCc1nc(CSCCN/C(=C\[N+](=O)[O-])NC)cs1</smiles>

(i)

Figure 1. Chemical structures and labels of Nizatidine and its impurities. (a) Nizatidine: $N$-(2-[(2-[(dimethylamino)methyl] thiazol-4-yl)methylthio]ethyl)- $N$-methyl-2-nitroethene-1,1-diamine; (b) Impurity-1: 4-chloromethyl-2-dimethylaminomethyl thiazole.; (c) Impurity-2: 2-Dimethylaminomethyl-4-hydroxymethylthiazole.; $\quad$ (d) Impurity-3: N, N-bis[2-[[[2-[(dimethylamino) -methyl]-4-thiazolyl]methyl]thio]ethyl]-2-nitro-1, 1-ethenediamine; (e) Impurity-4: $\mathrm{N}-[2-[[[2-[(d i m e t h y l a m i n o) m e t h y l]-4-$ thiazolyl] methyl]thio]ethyl]-2-nitro-1-thiomethyl etheneamine; (f) Impurity-5: 2-[[[2-[(dimethylamino)methyl]-4-thiazolyl] methyl]thio]ethyl-N'-methyl-2-nitro-1, 1-ethenediamine.; (g) Impurity-6: N-Methyl-S-methyl-2-nitroethene; (h) Impurity-7: Bis-N-methyl-2-nitro ethane; (i) Impurity-8: N-methyl-N'-\{2-[(\{2-[(methylamino)methyl]-1, 3-thiazol-4-yl\}methyl)sulfanyl] ethyl\}-2-nitroethene-1, 1-diamine. 


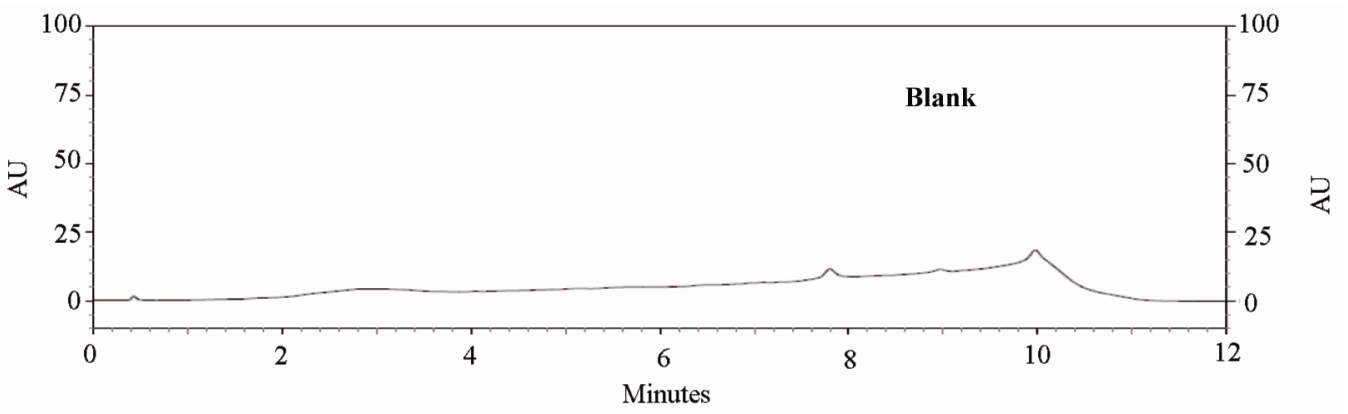

(a)

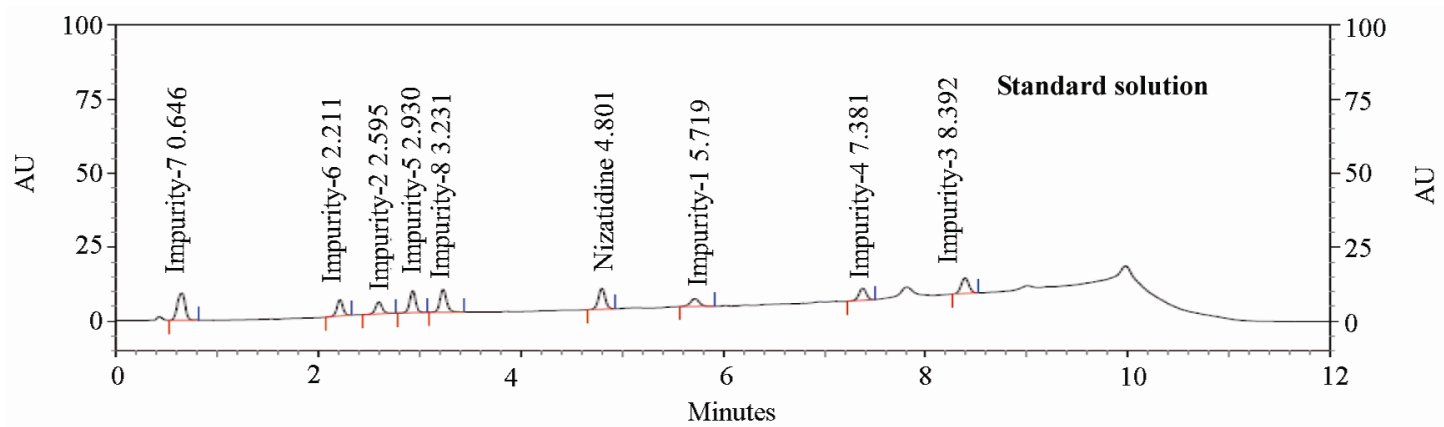

(b)

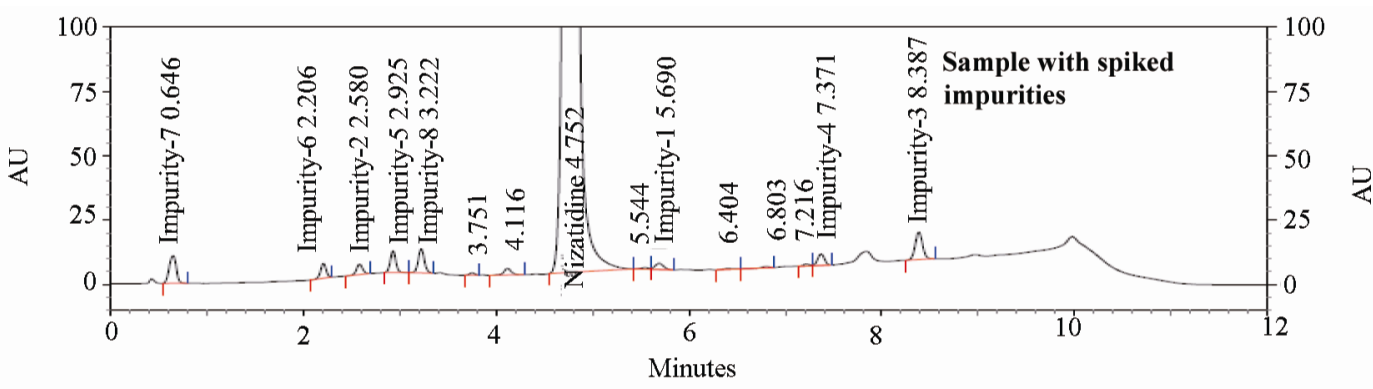

(c)

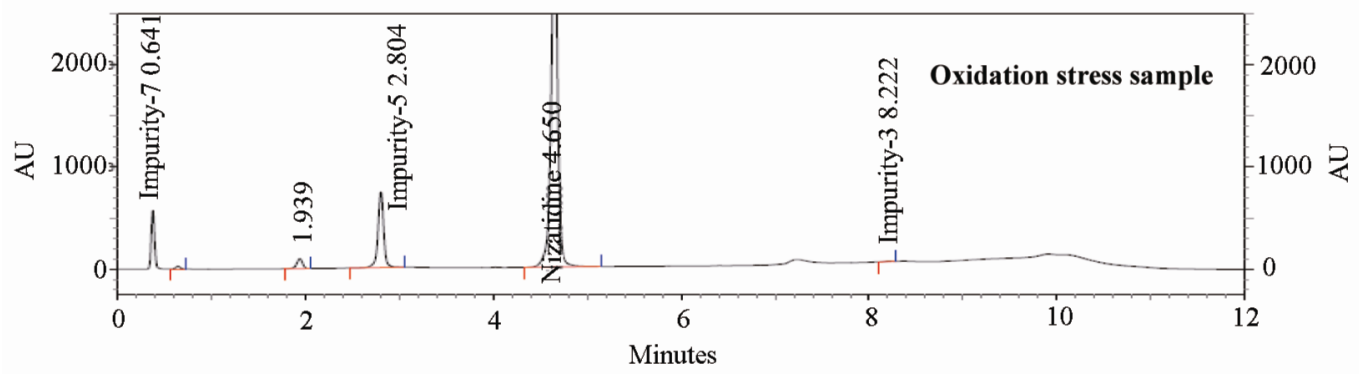

(d)

Figure 2. Typical chromatogram of blank, standard solution and Nizatidine spiked with impurities \& Oxidation Stress sample Chromatograms.

curve are calculated for the both chromatographic purity and assay methods.

\subsubsection{Accuracy}

A known amount of the impurity stock solutions are spiked to the previously analysed samples at LOQ, 100 and $150 \%$ of the analyte concentration $\left(2000 \mu \mathrm{g} \cdot \mathrm{mL}^{-1}\right)$. The percentage of recoveries for impurity-1, impurity-2, impurity-3, impurity-4, impurity-5, impurity-6, impurity7 and impurity-8 are calculated. A known amount of 
Table 3. Linearity table.

\begin{tabular}{|c|c|c|c|c|c|c|}
\hline & Component & Trendline equation & Range (\%) & Correlation coefficient & \% Intercept & Residual sum of squares \\
\hline & Impurity-1 & $1750623 x+9520$ & $0.03-0.225$ & 0.99990 & 3.50 & 15012852 \\
\hline & Impurity-2 & $1975909 x-2112$ & $0.03-0.225$ & 0.99992 & -0.71 & 16484761 \\
\hline & Impurity-3 & $3232271 x-11683$ & $0.03-0.225$ & 0.99988 & -2.45 & 64548028 \\
\hline & Impurity-4 & $2371566 x-11417$ & $0.03-0.225$ & 0.99996 & -3.30 & 11639064 \\
\hline & Impurity-5 & $3361838 x+2813$ & $0.03-0.225$ & 0.99986 & 0.55 & 78624095 \\
\hline & Impurity-6 & $2483388 x-3070$ & $0.03-0.225$ & 0.99988 & -0.83 & 37753954 \\
\hline & Impurity-7 & $5166943 x+13087$ & $0.03-0.225$ & 0.99978 & 1.64 & 297093973 \\
\hline & Impurity-8 & $3692683 x+3236$ & $0.03-0.225$ & 0.99992 & 0.59 & 57327237 \\
\hline \multirow{2}{*}{ Nizatidine } & Chromatographic purity & $5453849 x-710$ & $0.02-0.15$ & 0.99999 & -0.13 & 7728567 \\
\hline & Assay determination & $154040 x-292587$ & $50-150$ & 0.99998 & -0.96 & 17933996390 \\
\hline
\end{tabular}

Table 4. Table for accuracy study

\begin{tabular}{|c|c|c|c|c|c|c|c|c|c|c|}
\hline \multirow{3}{*}{$\begin{array}{l}\text { Amount of impurity } \\
\text { added }(\mu \mathrm{g}) \text { to the } \\
100 \% \text { sample }\end{array}$} & \multicolumn{10}{|c|}{$\%$ of Recovery } \\
\hline & \multirow{2}{*}{ Imp-1 } & \multirow{2}{*}{ Imp-2 } & \multirow{2}{*}{ Imp-3 } & \multirow{2}{*}{ Imp-4 } & \multirow{2}{*}{ Imp-5 } & \multirow{2}{*}{ Imp-6 } & \multirow{2}{*}{ Imp-7 } & \multirow{2}{*}{ Imp-8 } & \multicolumn{2}{|c|}{ Assay determination } \\
\hline & & & & & & & & & $\begin{array}{l}\text { Amount of sub- } \\
\text { stance added }\end{array}$ & $\begin{array}{l}\text { \%Recovery } \\
\text { (Nizatidine) }\end{array}$ \\
\hline 0.6 & 98.8 & 93.9 & 94.5 & 98.0 & 92.6 & 94.2 & 92.1 & 96.0 & $50 \%$ & 99.2 \\
\hline 3.0 & 91.9 & 103.1 & 104.3 & 106.3 & 99.0 & 105.7 & 104.4 & 102.2 & $100 \%$ & 101.3 \\
\hline 4.5 & 94.3 & 106.5 & 100.4 & 100.2 & 102.3 & 99.7 & 102.3 & 103.0 & $150 \%$ & 100.5 \\
\hline
\end{tabular}

Nizatidine stock solution spiked to the sucrose at 50\%, $100 \%$ and $150 \%$ of the analyte concentration (200 $\left.\mu \mathrm{g} \cdot \mathrm{mL}^{-1}\right)$. Each concentration level is prepared for three times. The percentage of recovery is calculated.

\subsubsection{Robustness}

To determine the robustness of the developed method, experimental conditions are deliberately changed and the resolution between each component is evaluated. The flow rate of the mobile phase is $1.5 \mathrm{~mL} \cdot \mathrm{min}^{-1}$. To study the effect of flow rate on the resolution, 0.2 units changed i.e. 1.3 and $1.7 \mathrm{~mL} \cdot \mathrm{min}^{-1}$. The effect of column temperature on resolution is studied at $25^{\circ} \mathrm{C}$ and $35^{\circ} \mathrm{C}$ instead of $30^{\circ} \mathrm{C}$. The above all varied conditions done at two single matrix analysis and the components of the mobile phase were held constant.

\subsubsection{Robustness Change 1 (Lower):}

Flow rate-1.3 $\mathrm{mL} \cdot \mathrm{min}^{-1}$, Column oven temperature $-25^{\circ} \mathrm{C}$.

Gradient program is $0 / 4,2 / 12,7 / 37,9 / 47,10 / 4$ and 12/4 (time (min)/\% B).

\subsubsection{Robustness Change 2 (Upper):}

Flow rate-1.7 $\mathrm{mL} \cdot \mathrm{min}^{-1}$, Column oven temperature $-35^{\circ} \mathrm{C}$.

Gradient program is $0 / 0,2 / 8,7 / 33,9 / 43,10 / 0$ and $12 / 0$ (time (min)/\% B).

\subsubsection{Solution Stability and Mobile Phase Stability}

The solution stability of Nizatidine and its related impurities are carried out by leaving spiked sample solution in tightly capped volumetric flask at room temperature for $48 \mathrm{~h}$. Impurity content is determined for every $6 \mathrm{~h}$ interval up to the study period. Mobile phase stability is also carried out for $48 \mathrm{~h}$ by injecting the freshly prepared sample solutions for every $6 \mathrm{~h}$ interval. Impurity content and assay is checked in the test solutions. Mobile phase prepared is kept constant during the study period.

\section{Results and Discussions}

\subsection{Specificity and Stress Studies}

Stress studies on Nizatidine under different stress conditions suggested the following degradation behavior. (See Table 2)

\subsubsection{Degradation in Acid Stress Condition}

Nizatidine is exposed to $1 \mathrm{~N} \mathrm{HCl}$ upon heating for $2 \mathrm{~h}$ at 
Table 5.1. Table for batch analysis of assay.

\begin{tabular}{|c|c|c|c|c|c|c|c|c|c|}
\hline \multirow{2}{*}{ Trial } & \multicolumn{3}{|c|}{ As per USP } & \multicolumn{3}{|c|}{ As per Ph.Eur } & \multicolumn{3}{|c|}{ As per developed method } \\
\hline & B.No-01 & B.No-02 & B.No-03 & B.No-01 & B.No-02 & B.No-03 & B.No-01 & B.No-02 & B.No-03 \\
\hline I & 99.5 & 99.6 & 99.8 & 99.6 & 99.5 & 99.6 & 99.3 & 99.8 & 99.7 \\
\hline II & 99.4 & 99.7 & 99.7 & 99.4 & 99.8 & 99.8 & 99.8 & 99.6 & 99.4 \\
\hline III & 99.6 & 99.5 & 99.9 & 99.3 & 99.7 & 99.4 & 99.6 & 99.4 & 99.6 \\
\hline Average & 99.5 & 99.6 & 99.8 & 99.4 & 99.7 & 99.6 & 99.6 & 99.6 & 99.6 \\
\hline Stdev & 0.10 & 0.10 & 0.10 & 0.15 & 0.15 & 0.20 & 0.25 & 0.20 & 0.15 \\
\hline$\%$ RSD & 0.10 & 0.10 & 0.10 & 0.15 & 0.15 & 0.20 & 0.25 & 0.20 & 0.15 \\
\hline
\end{tabular}

$80^{\circ} \mathrm{C}$, no significant degradation is observed.

\subsubsection{Degradation in Base Stress Condition}

Nizatidine is exposed to $0.1 \mathrm{~N} \mathrm{NaOH}$ upon heating for 10 minutes at $80^{\circ} \mathrm{C}$, no significant degradation is observed.

\subsubsection{Degradation in Peroxide Stress Condition}

Nizatidine is more sensitive to the oxidative treatment, Nizatidine is undergone degradation with $10 \% \mathrm{H}_{2} \mathrm{O}_{2}$ of fresh preparation and prominent degradation is observed as impurity-5.

\subsubsection{Degradation in Neutral (Water) Stress Condition}

Nizatidine is exposed water upon heating for $2 \mathrm{~h}$ at $80^{\circ} \mathrm{C}$, no degradation is observed.

\subsubsection{Photolytic Stress Condition}

Nizatidine is exposed to light for an overall illumination of 1.2 million Klux hours and an integrated near ultraviolet energy of 200-watt hours/square meter (w/mhr) (in photo stability chamber), no significant degradation is observed.

\subsubsection{Thermal Stress Condition}

Nizatidine exposed to dry heat at $80^{\circ} \mathrm{C}$ for 24 hours, no degradation is observed.

The mass balance of stressed samples is close to $99.2 \%$. The assay of Nizatidine is unaffected in the presence of eight impurities and its degradation products confirm the stability indicating power of the developed method.

\subsection{Method Validation}

\subsubsection{Precision}

The \% RSD of area of Nizatidine, impurity-1, impurity-2, impurity-3, impurity-4, impurity-5, impurity-6, impurity- 7 and impurity- 8 and \% RSD of area \% of each impurity in precision study are within $2.0 \%$ confirming the good precision of the developed analytical method. The \% RSD obtained in intermediate precision study for
Nizatidine, impurity-2, impurity-3, impurity-4, impurity-5, impurity-6, impurity-7 and impurity-8 are well within $4.0 \%$, confirming the intermediate precision of the method. The \% RSD obtained in precision and intermediate precision studies for Nizatidine are well within $1.0 \%$ of assay determination method.

95\% confidence interval of mean calculated for both chromatographic purity and assay results at precision study.

\subsubsection{Sensitivity}

The limit of detection of Nizatidine, impurity-1, impurity-2, impurity-3, impurity-4, impurity-5, impurity-6, impurity-7 and impurity-8 is $0.006 \%$ (of analyte concentration, i.e. $2000 \mu \mathrm{g} \cdot \mathrm{mL}^{-1}$ ) for $10 \mu \mathrm{L}$ injection volume. The limit of quantification of Nizatidine, impurity-1, impurity-2, impurity-3, impurity-4, impurity-5, impurity-6, impurity-7 and impurity- 8 is $0.03 \%$ (of analyte concentration, i.e. $2000 \mu \mathrm{g} \cdot \mathrm{mL}^{-1}$ ) for $10 \mu \mathrm{L}$ injection volume. The $\%$ RSD for area of Nizatidine, impurity-1, impurity-2, impurity-3, impurity-4, impurity-5, impurity-6, impurity-7 and impurity-8 are below 5 for precision at LOQ level.

\subsubsection{Linearity and Range}

Calibration curve obtained by the least square regression analysis between average peak area and concentration showed linear relationship with a correlation coefficient of 0.999 over the calibration ranges tested. Linear calibration plot for chromatographic purity method is obtained over the calibration ranges tested, i.e. LOQ to $0.225 \%$ for impurity-1, impurity-2, impurity-3, impurity4, impurity-5, impurity-6, impurity-7 \& impurity-8 and LOQ to $0.15 \%$ for Nizatidine. The correlation coefficient obtained is greater than 0.999 for all eight impurities and Nizatidine. The result shows an excellent correlation existed between the peak area and concentration of Nizatidine and all impurities. Linear calibration plot for assay determination method is obtained over the calibration ranges tested, i.e. $50 \%$ to $150 \%$ for Nizatidine and found the correlation coefficient more than 0.9999.The results shows an excellent correlation existed between the peak area and concentration of Nizatidine in assay determina- 
Table 5.2. Table for Batch analysis of Chromatographic purity

\begin{tabular}{|c|c|c|c|c|c|c|c|c|c|}
\hline \multirow{3}{*}{ Component } & \multicolumn{9}{|c|}{ B.No-01 } \\
\hline & \multicolumn{3}{|c|}{ As per USP } & \multicolumn{3}{|c|}{ As per Ph.Eur } & \multicolumn{3}{|c|}{ As per developed method } \\
\hline & Trial-I & Trial-II & Trial-III & Trial-I & Trial-II & Trial-III & Trial-I & Trial-II & Trial-III \\
\hline Impurity-1 & ND & ND & ND & ND & ND & ND & ND & ND & ND \\
\hline Impurity-2 & ND & ND & ND & ND & ND & ND & ND & ND & ND \\
\hline Impurity-3 & 0.10 & 0.09 & 0.09 & 0.08 & 0.09 & 0.08 & 0.10 & 0.10 & 0.09 \\
\hline Impurity-4 & 0.04 & 0.03 & 0.04 & 0.03 & 0.04 & 0.05 & 0.05 & 0.05 & 0.04 \\
\hline Impurity-5 & 0.03 & 0.03 & 0.04 & 0.04 & 0.03 & 0.04 & 0.03 & 0.03 & 0.03 \\
\hline Impurity-6 & ND & ND & ND & ND & ND & ND & ND & ND & ND \\
\hline Impurity-7 & 0.03 & 0.03 & 0.02 & 0.03 & 0.02 & 0.03 & 0.03 & 0.03 & 0.03 \\
\hline Impurity-8 & 0.04 & 0.03 & 0.03 & 0.04 & 0.04 & 0.03 & 0.03 & 0.04 & 0.03 \\
\hline MSUI & 0.04 & 0.04 & 0.05 & 0.04 & 0.03 & 0.03 & 0.05 & 0.05 & 0.04 \\
\hline TI & 0.35 & 0.37 & 0.34 & 0.33 & 0.32 & 0.34 & 0.37 & 0.39 & 0.36 \\
\hline \multicolumn{10}{|c|}{ B.No-02 } \\
\hline Impurity-1 & ND & ND & ND & ND & ND & ND & ND & ND & ND \\
\hline Impurity-2 & ND & ND & ND & ND & ND & ND & ND & ND & ND \\
\hline Impurity-3 & 0.09 & 0.08 & 0.08 & 0.08 & 0.08 & 0.08 & 0.09 & 0.08 & 0.08 \\
\hline Impurity-4 & 0.04 & 0.03 & 0.04 & 0.03 & 0.04 & 0.05 & 0.05 & 0.05 & 0.04 \\
\hline Impurity-5 & 0.03 & 0.03 & 0.04 & 0.04 & 0.03 & 0.04 & 0.03 & 0.03 & 0.03 \\
\hline Impurity-6 & ND & ND & ND & ND & ND & ND & ND & ND & ND \\
\hline Impurity-7 & 0.03 & 0.03 & 0.02 & 0.03 & 0.02 & 0.03 & 0.03 & 0.03 & 0.03 \\
\hline Impurity-8 & 0.04 & 0.04 & 0.03 & 0.04 & 0.04 & 0.04 & 0.04 & 0.04 & 0.03 \\
\hline MSUI & 0.04 & 0.05 & 0.05 & 0.05 & 0.04 & 0.03 & 0.04 & 0.04 & 0.04 \\
\hline TI & 0.33 & 0.32 & 0.34 & 0.35 & 0.37 & 0.36 & 0.33 & 0.31 & 0.34 \\
\hline \multicolumn{10}{|c|}{ B.No-03 } \\
\hline Impurity-1 & ND & ND & ND & ND & ND & ND & ND & ND & ND \\
\hline Impurity-2 & ND & ND & ND & ND & ND & ND & ND & ND & ND \\
\hline Impurity-3 & 0.09 & 0.09 & 0.08 & 0.09 & 0.09 & 0.10 & 0.08 & 0.09 & 0.09 \\
\hline Impurity-4 & 0.04 & 0.04 & 0.04 & 0.04 & 0.04 & 0.03 & 0.04 & 0.03 & 0.05 \\
\hline Impurity-5 & 0.03 & 0.03 & 0.04 & 0.04 & 0.04 & 0.03 & 0.04 & 0.04 & 0.04 \\
\hline Impurity-6 & ND & ND & ND & ND & ND & ND & ND & ND & ND \\
\hline Impurity-7 & 0.03 & 0.02 & 0.03 & 0.02 & 0.03 & 0.03 & 0.03 & 0.03 & 0.02 \\
\hline Impurity-8 & 0.03 & 0.03 & 0.03 & 0.03 & 0.02 & 0.03 & 0.03 & 0.03 & 0.03 \\
\hline MSUI & 0.05 & 0.06 & 0.06 & 0.04 & 0.06 & 0.05 & 0.06 & 0.05 & 0.05 \\
\hline TI & 0.38 & 0.40 & 0.41 & 0.39 & 0.37 & 0.40 & 0.36 & 0.39 & 0.41 \\
\hline
\end{tabular}

ND-Not detected 
tion method (See Figure 3, Table 3).

Theoretical response calculated for each component with Trendline equation and also calculated residuals, residual sum of squares and sensitivity plot (Response for unit concentration) of each component. There is no trend in residuals and sensitivity plot obtained within the specified range.

\subsubsection{Accuracy}

The percentage recovery of impurity-1, impurity-2, impurity-3, impurity-4, impurity-5, impurity-6, impurity-7 and impurity-8, in Active pharmaceutical Ingredient (API) samples ranged from 91.9 to 106.5 . LC chromatogram of spiked sample with four impurities in Nizatidine sample is shown in Figure 2(b). The percentage recovery of Nizatidine in assay determination method ranged from 99.2 to 101.3 (See Table 4).

\subsubsection{Robustness}

Close observation of analysis results for deliberately changed chromatographic conditions (flow rate and column temperature) revealed that the resolution between closely eluting impurities, namely impurity-5 and impurity- 8 is greater than 2.5 , illustrating the robustness of the method.

And also done system precision and method precision studies in robustness conditions. The \% RSD of area of Nizatidine, impurity-1, impurity-2, impurity-3,impurity-4, impurity-5, impurity-6, impurity-7 and impurity-8 and \% RSD of area \% of each impurity in robustness study for replicate injections and preparations $(n=3)$ are within $5.0 \%$ confirming the good precision of method in robustness conditions.

\subsubsection{Solution Stability and Mobile phase Stability}

The \% RSD of assay of Nizatidine during solution stability and mobile phase stability experiments is within 1.0. No significant changes are observed in the content of

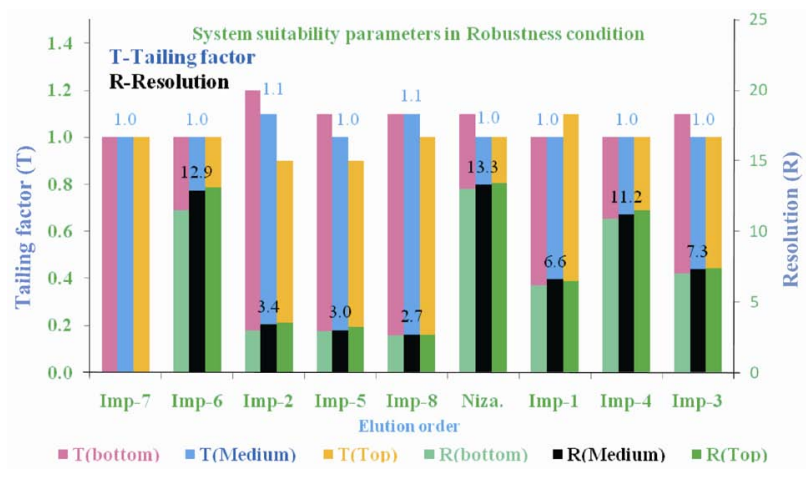

Figure 3. Typical chart for comparison of system suitability parameters in Robustness condition with as such condition (Medium). impurity-1, impurity-2, impurity-3, impurity-4, impurity5, impurity-6, impurity-7 and impurity-8 during solution stability and mobile phase stability experiments. The solution stability and mobile phase stability experiments data confirms that sample solutions and mobile phase used chromatographic purity and assay determination are stable up to the study period of $48 \mathrm{~h}$.

\subsubsection{Comparative analysis}

Three consecutive batches are selected and analyzed as per USP, Ph.Eur methods as well as developed method for both chromatographic purity and assay by HPLC for three times and the percentage of each impurity and assay results are compared for three methods. The USP and Ph.Eur methods results are comparable with the new developed method (See Table 5).

\section{Conclusions}

The Stability indicating fast LC method for Nizatidine and its impurities Quantification is developed and validated as per ICH requirements. The gradient RRLC method developed and used for stress studies is also fit for quantitative, chromatographic purity and assay determination of Nizatidine. The developed method is stability indicating which can be used for the impurity testing and assay determination in routine analysis of production samples and also to analyze stability samples.

\section{Acknowledgements}

The authors wish to thank the management of Shasun chemicals and drugs Limited for supporting this work.

\section{References}

[1] M. Atmaca, M. Kuloglu, E. Tezcan, B. Ustundag and N. Kilic, "Nizatidine for the Treatment of Patients with Quetiapine-Induced Weight Gain,” Hum Psychopharmacol, Vol. 19, No. 1, 2004, pp. 37-40. doi:10.1002/hup.477

[2] PRNewswire, "Eli Lilly and Company and Reliant Pharmaceuticals Announce Agreement for U.S. Sales and Marketing Rights to Axid (R)," Indianapolis, September 7, 2000.

[3] F. Parente and G. B. Porro, “Acid Inhibitory Characteristics of Nizatidine in Man: An Overview, "Scandinavian Journal of Gastroenterology, Vol. 29, No. s206, 1994, pp. 3-7. doi:10.3109/00365529409091413

[4] The United States Pharmacopoeia 32 National Formulary 27. (USP)

[5] European Pharmacopoeia 4.2, Council of Europe, 2002, pp. 2737-2739.

[6] U. D. Neue, D. McCabe, V. Ramesh, H. Pappa, J. DeMuth, "Transfer of HPLC Procedures to Suitable Col- 
umns of Reduced Dimensions and Particle Sizes,” Pharmacopeial Forum, Vol. 35, No. 6, 2009, pp.1622-1626.

[7] International Conference on Harmonization (ICH), "Stability Testing of New Drug Substances and Products,” ICH Topic Q1A (R2), ICH Secretariat, Geneva, 2005.

[8] International Conference on Harmonization (ICH), "Photostability Testing of New Drug Substances and Products,” ICH Q1B Guidline, ICH Secretariat, Geneva, 2005.

[9] S. W. Baertschi, K. Alsante and R. A. Reed, "Pharmaceutical Stress Testing: Predicting Drug Degradation,” Drugs and the Pharmaceutical Sciences, Vol. 153, 2005, pp. 1- 482. doi:10.1201/9780849359194.ch3

[10] US FDA guidance, "Analytical Procedures and Methods Validation,” Food and Drug Administration, Rockville, 2000.
[11] The United States Pharmacopeial Convention, "Validation of Compendial Methods <1225>," The United States Pharmacopeia, Rockville, 2009.

[12] M. E. Swartz and I. S. Krull, "Developing and Validating Stability-Indicating Methods by Michael Swartz and Ira Krull,” LC-GC North America, 2005.

[13] International Conference on Harmonization (ICH), "Validation of Analytical Procedures: Text and Methodology,” Q2 (R1), ICH Secretariat, Geneva, 2005.

[14] J. Ermer and J. H. McB. Miller, "Method Validation in Pharmaceutical Analysis: A Guide to Best Practice," Wiley-VCH, enero, 2005.

[15] D. M. Bliesner, "Validating Chromatographic Methods: A Practical Guide,” Wiley, Hoboken, 2006, pp.1-304. 